\title{
Renal biomarkers and prognosis in acute pulmonary embolism
}

\section{Thomas M Berghaus, Martin Schwaiblmair, Wolfgang von Scheidt}

Renal dysfunction has become a validated prognostic factor indicating increased morbidity and mortality in different cardiovascular diseases, such as acute coronary syndrome ${ }^{1}$ or chronic heart failure. ${ }^{2}$ Impaired kidney function may not only reflect chronic renal disease but also deterioration secondary to haemodynamic disturbances, as decreased cardiac output and elevated central venous pressure may contribute to renal insufficiency. ${ }^{3}$ Kidney dysfunction has previously been observed in patients with acute pulmonary embolism (APE) and was found to be associated with worse shortterm outcomes. ${ }^{45}$ However, those studies were not able to distinguish between acute kidney injury due to haemodynamic compromise cause by APE or chronic preexisting renal insufficiency.

Kostrubiec and co-workers ${ }^{6}$ investigated markers of acute kidney injury such as cystatin $\mathrm{C}$ and serum neutrophil gelatinase-associated lipocalin (N-GAL) and their association with left and right heart function, disease severity, and prognosis in patients with APE. Cystatin C is a $13 \mathrm{kDa}$ endogenous cysteine proteinase inhibitor and is produced by nucleated cells at a constant rate. It is freely filtered by the glomerulus, reabsorbed and catabolised, but it is not secreted by the tubules. Earlier studies demonstrated the superiority of serum cystatin C compared with creatinine, especially to detect minor changes in glomerular filtration rate (GFR). ${ }^{7}$ In addition, it was suggested that serum cystatin $C$ performed better than creatinine as a marker to detect acute GFR reductions. ${ }^{8}$ The release of N-GAL represents an intrinsic response of the proximal renal tubule cells to ischaemic injury of the kidney. In the animal model, the response is extremely rapid, with N-GAL appearing in the first urine portion after

Department of Cardiology, Respiratory Medicine and Intensive Care, Klinikum Augsburg, Ludwig-Maximilians-University Munich, Germany

Correspondence to Dr Thomas M Berghaus, Klinikum Augsburg, Stenglinstrasse 2, D - 86156 Augsburg, Germany; thomas.berghaus@klinikum-augsburg.de the acute kidney injury. ${ }^{9}$ Serum N-GAL elevation was found to indicate acute GFR reductions much faster than creatinine measurements in different clinical conditions, for example, in patients undergoing cardiac surgery ${ }^{10}$ or percutaneous coronary interventions. ${ }^{11}$ The determination of cystatin $\mathrm{C}$ and serum N-GAL might thus be appropriate tools for detecting acute kidney injury secondary to haemodynamic compromise or hypoxaemia resulting from APE.

The authors investigated 142 consecutive patients with APE. The all-cause mortality rate up to 30 days after the diagnosis of APE was $10 \%$, nine deaths (6\%) were found to be pulmonary embolism related. The estimated glomerular filtration rate (eGFR) was noted to be $60 \mathrm{ml} / \mathrm{min}$ per $1.73 \mathrm{~m}^{2}$ or less in $48 \%$ of the study population. Both, N-GAL and cystatin C levels significantly correlated with the eGFR. In contrast to cystatin C, serum N-GAL concentrations were significantly higher in patients who died from APE. Decrease in eGFR as well as elevations of cystatin $\mathrm{C}$ and serum N-GAL were significant predictors of all-cause and pulmonary embolism-related 30-day mortality in univariate analysis. However, only cystatin $\mathrm{C}$ levels independently predicted 30-day all-cause mortality but not PE-related deaths in the multivariate analysis. Both cystatin C and N-GAL elevations were associated with less favourable clinical outcomes in the Kaplan-Meier analysis. Left ventricular ejection fractions correlated with both eGFR and cystatin C levels, while plasma $\mathrm{N}$-GAL concentrations were found to correlate with right ventricular function parameters assessed by echocardiography. Other risk stratification models such as the simplified pulmonary embolism severity index significantly correlated with eGFR, cystatin C levels and serum N-GAL concentrations.

In contrast to previous studies ${ }^{4}$ the authors were able to demonstrate that haemodynamic compromise during APE might have contributed to renal dysfunction, as markers of acute kidney injury were associated with signs of acute right ventricular dysfunction or increased central venous pressure. Sudden pressure overload in the pulmonary circulation due to APE may lead to acute right ventricular dysfunction along with tricuspid regurgitation. As a consequence, central venous pressure rises and may lead to renal dysfunction by a stagnation of venous blood flow in the kidneys. ${ }^{12}$ The findings of the study are new and possibly represent an important step forward in the understanding of the interactions between the cardiopulmonary and renal systems during APE. On the other hand, the study included many patients with relevant comorbidities, such as diabetes mellitus and congestive heart failure, which are well known to affect kidney function themselves. As a consequence, the eGFR was found to be reduced in nearly one out of two study participants. Therefore, both cystatin $\mathrm{C}$ and N-GAL elevations might have been aggravated by chronic preexisting renal insufficiency.

The results of the present study underline the notion that renal dysfunction may be associated with a worse prognosis of patients with APE and, therefore, might represent an additional aspect in risk stratification. A number of clinical and instrumental findings such as haemodynamic instability, right ventricular dysfunction or myocardial injury have been associated with a high risk of adverse short-term clinical outcomes in patients with APE and are the basis of risk stratification according to current guidelines. ${ }^{13}$ Therefore, particularly in haemodynamically stable patients who are believed to be at low risk of death, markers of acute kidney injury might be additionally helpful in risk stratification, as signs of right ventricular dysfunction or myocardial injury are missing and both cystatin $\mathrm{C}$ and N-GAL elevations showed very high negative predictive values in the estimation of the all-cause mortality in this subgroup of patients. However, the results of this single-centre trial have to be interpreted with caution, as the statistical analysis is limited by the relatively small numbers of study participants and the low death rates. For example, the evaluation for pulmonary embolism-related 30 day mortality is based on the outcome analysis of only nine patients. The small study size might explain the partially inconsistent findings of the study, as the results might have been biased by concomitant factors such as age or comorbidity even after forward stepwise multivariate analysis. 
Is the evaluation of renal function a new aspect in the risk stratification of patients with APE? The study of Kostrubiec and colleagues ${ }^{6}$ is promising, but it is too early to answer the question. Larger multicentre studies need to follow, and markers of acute kidney injury have to be validated against other biomarkers such as brain-type natriuretic peptide or troponin, which are already accepted components in risk stratifications models of patients with APE. ${ }^{14}$

Competing interests None.

Provenance and peer review Commissioned; externally peer reviewed.

Heart 2012;98:1185-1186.

doi:10.1136/heartjnl-2012-302298

\section{REFERENCES}

1. Al Suwaidi J, Reddan DN, Williams K, et al; Platelet $\mathrm{llb} / \mathrm{lll}$ a Antagonism for the Reduction of Acute coronary syndrome events in a Global Organization Network. Prognostic implications of abnormalities in renal function in patients with acute coronary syndromes. Circulation 2002;106:974-80.
2. Damman K, Navis G, Voors AA, et al. Worsening renal function and prognosis in heart failure: systematic review and meta-analysis. J Card Fail 2007:8:599-608.

3. Damman K, van Deursen VM, Navis G, et al. Increased central venous pressure is associated with impaired renal function and mortality in a broad spectrum of patients with cardiovascular disease. J Am Coll Cardiol 2009;53:582-8.

4. Kostrubiec M, Łabyk A, Pedowska-Włoszek J, et al. Assessment of renal dysfunction improves troponinbased short-term prognosis in patients with acute symptomatic pulmonary embolism. J Thromb Haemost 2010;8:651-8.

5. Berghaus TM, Behr W, von Scheidt W, et al. The $\mathrm{N}$-terminal pro-brain-type natriuretic peptide based short-term prognosis in patients with acute pulmonary embolism according to renal function. J Thromb Thrombolysis 2012;33:58-63.

6. Kostrubiec M, Łabyk A, Pedowska-Włoszek J, et al. Neutrophil gelatinase-associated lipocalin, cystatin $\mathrm{C}$ and eGFR indicate acute kidney injury and predict prognosis of patients with acute pulmonary embolism. Heart 2012; 98 . 1221-8.

7. Mussap M, Dalla Vestra M, Fioretto P, et al. Cystatin $C$ is amore sensitive marker than creatinine for the estimation of GFR in type 2 diabetic patients. Kidney Int 2002;61:1453-61.
8. Herget-Rosenthal $\mathbf{S}$, Marggraf G, Hüsing J, et al. Early detection of acute renal failure by serum cystatin C. Kidney Int 2004;66:1115-22.

9. Mishra J, Ma 0, Prada A, et al. Identification of neutrophil gelatinase-associated lipocalin as a novel early urinary biomarker for ischemic renal injury. J Am Soc Nephrol 2003;14:2534-43.

10. Mishra J, Dent C, Tarabishi R, et al. Neutrophil gelatinase-associated lipocalin (NGAL) as a biomarker for acute renal injury after cardiac surgery. Lancet 2005; 365:1231-8

11. Bachorzewska-Gajewska H, Malyszko J Sitniewska E, et al. Neutrophil-gelatinase-associated lipocalin and renal function after percutaneous coronary interventions. Am J Nephrol 2006;26:287-92.

12. Piazza G, Goldhaber SZ. The acutely decompensated right ventricle: pathways for diagnosis and management. Chest 2005;128:1836-52.

13. Torbicki A, Perrier A, Konstantinides S, et al. Guidelines on the diagnosis and management of acute pulmonary embolism: the Task Force for the diagnosis and Management of acute pulmonary embolism of the European Society of Cardiology (ESC). Eur Heart J 2008;29:2276-315.

14. Vuilleumier N, Le Gal G, Verschuren F, et al. Cardiac biomarkers for risk stratification in non-massive pulmonary embolism: a multicenter prospective study. J Thromb Haemost 2009;7:391-8.

Heart now has an impact factor of $\mathbf{4 . 2 2 3}$ which reflects the high quality of the publication in the cardiology field. If you would like to add to this quality, then submit your paper at heart.bmj.com. 


\section{Heart}

\section{Renal biomarkers and prognosis in acute pulmonary embolism}

Thomas M Berghaus, Martin Schwaiblmair and Wolfgang von Scheidt

Heart 2012 98: 1185-1186

doi: 10.1136/heartjnl-2012-302298

Updated information and services can be found at:

http://heart.bmj.com/content/98/16/1185.full.html

\section{These include:}

References This article cites 14 articles, 4 of which can be accessed free at: http://heart.bmj.com/content/98/16/1185.full.htmI\#ref-list-1

Email alerting Receive free email alerts when new articles cite this article. Sign up in service the box at the top right corner of the online article.

Topic Articles on similar topics can be found in the following collections Collections
Venous thromboembolism (437 articles)
Epidemiology (3246 articles)
Drugs: cardiovascular system (7896 articles)
Hypertension (2679 articles)
Clinical diagnostic tests (4371 articles)
Echocardiography (1923 articles)
Interventional cardiology (2670 articles)
Percutaneous intervention (875 articles)

Notes

To request permissions go to:

http://group.bmj.com/group/rights-licensing/permissions

To order reprints go to:

http://journals.bmj.com/cgi/reprintform

To subscribe to BMJ go to:

http://group.bmj.com/subscribe/ 